УДК 811.111'42:82-1

DOI https://doi.org/10.52726/as.humanities/2021.3.21

\author{
М. С. СТЕРЛІКОВА \\ асистентка кафедри англійської мови, \\ Чернівецький національний університет імені Юрія Федьковича, м. Чернівці, Украӥна \\ Електронна пошта: m.sterlikova@chnu.edu.ua \\ http://orcid.org/0000-0002-2010-5518
}

\title{
ФУНКЦІОНУВАННЯ ІМЕННИКІВ У ПІСЕННОМУ ДИСКУРСІ 2010-Х РР.
}

У цій статті розглядаються особливості використання іменників у текстах пісень британської незалежної сцени 2010-х років. Іменники, які є об’єктом дослідження, використовуються авторами пісень для позначення конкретних культурно мотивованих явищ та передачі універсальних концептів, властивих кожній людині. Лінгвісти всіх теоретичних напрямів згодні з тим, що лексична категорійність є однією з найважливіших і найскладніших проблем у лінгвістиці. Одне з головних питань категорійності: чи існує універсальний семантичний критерій, який мотивує приналежність до категорії окремою мовою i, ширше, у різних мовах? Більшість сучасних лінгвістів, особливо ті, хто підходить до цієї проблеми з функціоналістської та когнітивної точок зору, слідом за традиційними граматистами вважають пошук умовних універсалій, які лежать в основі приналежності до категорій, продуктивною дослідницькою програмою. Слід зазначити, що вирішальним моментом у дослідженні семантичних класів іменників є екстралінгвістичне середовище, тобто зовнішні чинники, які спонукали автора використати певні лексичні одиниці. Логічно припустити, що кожна людина наділяє лексичні одиниці унікальним, властивим лише ій змістом, і у зв'язку з цим ми стикаємося з декількома способами інтерпретації тексту пісні: через призму автора пісні та через призму аудиторії. Автором текстів пісень гурту Bring Me The Horizon переважно є Олівер Сайкс, уродженець Ешфорда, Кент, Англія. Географічне положення, безперечно, відіграло вирішальну роль у процесі написання текстів пісень, оскільки Bring Me The Horizon стали справжнім британським культурним феноменом. Оліверу Сайксу вдається не тільки зобразити досвід, який викликає відгук у його міжнародних шанувальників, а й інкорпорувати елементи, притаманні британській колективній свідомості. Проаналізувавши останній альбом гурту Bring Me The Horizon "Post Human: Survival Horror”, ми виділили наступні семантичні класи іменників: Heavenly Domain, Desperation, Violence, Animals, Habitat, Temporality, Ignorance, Emotional State. Це домінантні категорії, які Олівер Сайкс спробував донести до громадськості під час кризи COVID-19. Більш детальний огляд мотивів використання конкретних іменників міститься в емпіричній частині статті.

Ключові слова: семантика, семантичний аналіз, семантичні класи іменників, іменники, пісенний дискурс, дискурсні дослідження, британська незалежна музична сцена

Постановка проблеми. Здебільшого мова використовується для опису навколишньої дійсності. Однак у неї є так зване металінгвістичне використання, яке полягає в її застосуванні для отримання інформації про лінгвістичні механізми, що лежать у іiі основі. Семантика - застосування металінгвістичної функції мови для надання пояснень значенням слів. Семантика має комплексний характер, оскільки включає кількарівнів даних, відзначення мовних одиниць до значення речень, семантичних зв'язків між реченнями в дискурсі й прагматичних відносин.

Аналіз попередніх досліджень. Центральне місце у цій морфо-семантичній парадигмі займає пісенний дискурс, який став об'єктом пильної дослідницької уваги вітчизняних та закордонних мовознавців. Лінгвістичний аналіз дискурсу, зокрема текстовий i музичний аналізи, розвивалися паралельно i були присвячені вивченню подібних явищ. Пісенний дискурс $є$ прикладом міжособистісної комунікації, що містить певні смислові характеристики, зумовлені передусім лінгвістичними факторами. 3 семіотичної точки зору, музика та мова - це дві семіотичні системи, які характеризуються здатністю виробляти те, що ми можемо назвати значенням (єдиним чи множинним), маркуванням, позначенням, категоризацією тощо. У цих двох систем є дві загальні властивості: графіка та акустика. С. Чатман, В. Еко та Дж. М. Клінкенберг описують музику в графічному світлі і розглядають ії як «метамову» [Chatman et. al: 2019]. Ба більше, музика та мова утворюють два «хроносинтаксиси», перший з яких має синхронні або потенційно синхронні знаки, а другий - «несинхронні» [Chatman et. al: 2019]. Вербальна система має «подвійну артикуляцію», а музична - одинарну. 
Крім того, з генеративної точки зору, музика та мова використовують два схожі перцептивні канали: слуховий і візуальний, а також класифікують голос як канал виробництва.

Деякі вчені розглядають зв'язок між музикою та мовою як аналітичний інструмент. Таким чином, зв'язок між музикою та мовою знаходиться на методологічному рівні, оскільки об’єкт дослідження може бути змішаним, винятково музичним або винятково лінгвістичним [Сюта: 2010]. Цей напрям досліджень набув широкого поширення в епоху структуралізму. На відміну від використання музично-теоретичного апарату для аналізу вербальної мови, яка залишається відносно обмеженою, лінгвістичний апарат широко використовується для обліку музичних структур, у тому числі текстових. На додаток до цього все більше визнання отримує когнітивний підхід, у якому паралель між музикою та мовою грунтується на когнітивних механізмах, пов'язаних із розумінням цих двох систем. Такий підхід не обов'язково передбачає, що порівняння музики та мови знаходиться у центрі обговорення. Останній залишається недостатньо дослідженим, оскільки спостереження у сфері пізнання мови передували дослідженням у сфері сприйняття музики, а мова залишається ефективним та повсюдним інструментом порівняння. Як приклад можна навести роботу англійського дослідника Дж.А. Слободи [Sloboda: 1991] чи корпус досліджень, проведених 3. МакАдамсом протягом останніх тридцять років [McAdams: 1989].

Неможливо заперечувати внесок структурної епохи та, зокрема, запозичення музикознавством лінгвістичних моделей для аналізу тексту пісень. Вони дозволили точно визначити компоненти музичної системи, забезпечили музикознавство потужними аналітичними інструментами й у ширшому сенсі розвинули в аналізі обох систем прагнення точності, привчаючи аналітика до описової гостроти, без якої сьогодні важко обійтися. Але окрім цього, можливо, і насамперед ці підходи відкрили питання про аналітичні інструменти, тим самим забезпечивши певну концептуальну свободу, що сприяє усуненню дисциплінарних бар'єрів. Аналітичним інструментом, який лежить в основі нашого дослідження, є семантика. Семантика - дисципліна, яка вивчає смисловий складник мови та «закони, що регулюють трансформацію сенсу». Термін «семантика» грецького походження і утворений він від слова semantikos, похідного від прикметника semainein, що в перекладі означає «позначати» [Кронгауз: 2005]. Семантика визначає нашу компетентність в інтерпретації висловлювань та оцінці їхнього правильного формування. Ідентифікація та класифікація одиниць системи, інтерпеляція сенсу служить в основному для того, щоб виявити подібність та відмінність мовних елементів.

Класифікація лексики - частково питання осмислення самого лексикону шляхом внесення порядку у видимий безлад. До того ж лексикон - це не та сутність, яку можна розглядати лише з однієї перспективи. Існує безліч систем класифікації лексикону, оскільки він витканий з безлічі структур, бувши багатовимірним. Однією 3 найпоширеніших систем лексичної класифікації є класифікація за частинами мови. Останні класифікують лексику відповідно до iii комбінаторних граматичних властивостей: пасивна валентність, морфологічна комбінаторика тощо. Саме на цій класифікації грунтуються правила граматики. Вони належать не до окремої лексики, а до класів (дієслово, іменник загального роду, означальний прикметник тощо), а зазначені в них закономірності можуть застосовуватися до будь-якої лексики, якщо вона належить до певної частини мови. Цей аспект можна розглядати як виключно морфологічний, але варто пам'ятати, що наша робота зосереджена не лише на морфології, а й на семантиці. У цьому етапі ми можемо провести семантичну класифікацію лексичних одиниць. Для цього необхідно розробити системи, що базуються на змісті, переданому лексичними одиницями, повністю або значною мірою автономно від їхніх граматичних властивостей.

Доцільно запровадити термін «семантичне поле іменників», що наголошує на наявності специфічних семантичних компонентів у визначенні номінальних лексичних одиниць. Таким чином, семантичне поле іменників $є$ класом лексичних одиниць, кожна з яких має семантему, яка відповідає стратегічній позиції у визначенні, незалежно від того, чи є ця семантема центральним компонентом цього визначення. Ба більше, загальне визначення семантичного 
поля було висунуто британським лінгвістом Дж. Лайонсом: «Я пропоную визначити поняття “семантичне поле" в термінах певних відносин, які існують між елементами в конкретній лексичній підсистемі. Вони включають такі відносини, як схожість та відмінність значень, несумісність, антонімія тощо, які зазвичай розглядаються в рамках теорії значення» [4, с. 57]. М. А. Кронгауз стверджує, що сутність семантичних полів полягає переважно у розподілі термінів на категоріі: «Категоризацією називається процес віднесення об'єктів до відповідних семантичних класів» [Lyons, John 1995: 78]. Вчений наголошує, що класифікація мовних одиниць за допомогою семантичних категорій $\epsilon$ не лише методом, а й основною метою дослідження. Отже, ця стаття дасть краще уявлення про семантичні класи іменників у текстах пісень британського рок-гурту Bring Me the Horizon.

Мета нашого дослідження - дати морфосемантичний опис класу іменників, які зустрічаються у текстах пісень 2010-х років. Мета цієї роботи має двоспрямований характер: $з$ одного боку, вона може служити глосарієм іменників, які вживаються у певному культурному середовищі, а $з$ іншого боку, вона входить в сферу трансдисциплінарної лінгвістики (оскільки містить елементи структуралізму, когнітивної лінгвістики, соціолінгвістики тощо). Описовий метод, якого ми дотримуватимемося в цій статті, заснований на принципах морфо-семантичної класифікації іменників, оскільки ми вивчатимемо іменники не ізольовано, а в межах речень, у яких вони можуть фігурувати, прагнучі визначити їх основні властивості.

Виклад основного матеріалу. В композиції "DiE4u” ми зустрічаємо кілька іменників, які формують семантичне поле HEAVENLY DOMAIN у метафоричному сенсі, оскільки фронтмен Олівер Сайкс намагається донести до слухачів свою багаторічну боротьбу із залежністю:

"Let me see my halo, even though it's painful" [Bring Me The Horizon, Post Human: Survival Horror]

"I keep holding my breath for a miracle" [Bring Me The Horizon, Post Human: Survival Horror]

Після пережитої травми оповідач впадає у відчай. Отже, ми стикаємося із семантичним полем DESPERATION:
"Hoping the hole in my heart would heal somehow" [Bring Me The Horizon, Post Human: Survival Horror]

"Feeling so fucking close to the edge right now" [Bring Me The Horizon, Post Human: Survival Horror]

"And I'd write your name in a heart with the hemorrhage" [Bring Me The Horizon, Post Human: Survival Horror]

Наведені вище приклади демонструють лінгвістичний дуалізм пісенного тексту, який проявляється у необхідності приділяти увагу як морфологічному, так і семантичному змісту. Тут ми можемо спостерігати, як складені іменники надають ще більшої семантичної цінності музичній композиції.

Аналогічним чином, пісня, щодо якої ведеться дослідження, охоплює семантичне поле VIOLENCE:

"This isn't love, this is a car crash

This isn't love, this is a bloodbath

This isn't love, this is a sentence

It's a bullet in the head" [Bring Me The Horizon, Post Human: Survival Horror]

Вступні рядки до "Dear Diary" містять іменники, які можна віднести як до семантичного поля HEAVENLY DOMAIN, так і до VIOLENCE:

"The $s k y$ is falling, it's fucking boring

I'm going braindead, isolated

God is a shithead and we're his rejects" [Bring Me The Horizon, Post Human : Survival Horror]

За аналогією, іменник з наступного рядка $\epsilon$ частиною семантичного поля DESPERATION:

"I can't stomach any more Survival Horror" [Bring Me The Horizon, Post Human: Survival Horror].

За допомогою метафоричних конструкцій автор тексту пісні утворює семантичне поле ANIMALS:

Dear diary, I feel itchy like there's bugs under my skin

The $\boldsymbol{d o g}$ 's gone rabid (Shut the fuck up!) doing my head in" [Bring Me The Horizon, Post Human: Survival Horror]

Популярний вигук, на чолі якого стоїть іменник, належить до категорії HEAVENLY DOMAIN, перебуваючи в антонімічному зв'язку 3 центральною ідеєю семантичного поля: 
"I feel so hungry, what the hell is happening?" [Bring Me The Horizon, Post Human : Survival Horror]

Денотативна та конотативна мотивація наступних іменників сприяє створенню семантичного поля НАВITAT:

"Tasty, itchy, TV say there's no more human race

Kinda sad my whole entire existence been a waste

Ah, nevermind, it's not the end of the world, oh, wait" [Bring Me The Horizon, Post Human: Survival Horror]

Олівер Сайкс знову звертається до питань, пов'язаних з богом і потойбічним життям, але робить це 3 невірою, висловлюючи свою позицію щодо недостатньої участі небесних світил в усуненні страждання на землі:

"I'm a believer in nobody" [Bring Me The Horizon, Post Human: Survival Horror] - семантичне поле HEAVENLY DOMAIN. Безбожність та гнів на організовану релігію - поширений мотив у текстах Bring Me The Horizon.

"Don't call it a warning

This is a war" - [Bring Me The Horizon, Post Human : Survival Horror] семантичне поле VIOLENCE.

Наступні рядки, які утворюють семантичне поле DESPERATION, містять іменники, які, як відомо, колокуються у вирази зі значенням негативних емоцій (у випадку зі stomach: stomach ache, stomach bug, stomach cancer тощо). У цьому випадку квіти, про які йдеться, швидше за все, є квітами, які приносять на могилу для поминання померлих:

"Got a feeling in your stomach cause you know that it's coming for ya

Leave your flowers and grieve" [Bring Me The Horizon, Post Human: Survival Horror].

У черговому рядку Олівер Сайкс висловився про поширення теорій змови у світі останніми роками. Протягом 2020 року було поширено безліч фальшивих новин про вірус. Якщо говорити конкретніше, йдеться про антинаукові теорії змови. Отже, іменники, виділені курсивом та жирним шрифтом, $є$ частиною семантичного поля IGNORANCE:

"I heard they need better signal

Put chip and pins in the needles

Quarantine all of those secrets
In that black hole you call a brain before it's too late" [Bring Me The Horizon, Post Human : Survival Horror].

Семантичне поле DESPERATION:

"When life is a prison and death is the door" [Bring Me The Horizon, Post Human : Survival Horror]. Цей рядок може бути даниною поваги Тому Серлу, колишньому гітаристу Architects, який помер від раку, оскільки гурти є друзями один одного. У разі невиліковних хвороб життя стає нестерпним, і страждаючі відчувають, що немає сил підтримувати життєдіяльність.

y "Teardrops" Олівер Сайкс розмірковує про фундаментальну сутність людських емоцій, тому виникає семантичне поле EMOTIONAL STATE:

"Force-feed our fear until our hearts go numb

Addicted to a lonely kind of love" [Bring Me The Horizon, Post Human: Survival Horror].

Семантичне поле DESPERATION:

"I'm running outta teardrops, let it hurt till it stops

I can't keep my grip, I'm slipping away from me

Oh, God, everything is so fucked, but I can't feel a thing

The emptiness is heavier than you think" [Bring Me The Horizon, Post Human : Survival Horror]. Олівер Сайкс настільки пригнічений болем та розрухою навколо нього, що не в змозі висловити більше жодних емоцій.

Олівер Сайкс розповідає про свою попередню залежність від кетаміну, в якій він зізнався у 2014 році під час APMAs. Річ у тім, що словосполучення "as high as a kite" вживається у значенні наркотичного чи алкогольного сп'яніння і тому може бути віднесено до складника семантичного поля DESPERATION:

"High as a kite, I'm never coming down" [Bring Me The Horizon, Post Human: Survival Horror].

Семантичне поле VIOLENCE:

"Another day, another post-traumatic order" [Bring Me The Horizon, Post Human: Survival Horror]. Враховуючи, що приспів співається з погляду деспотичного режиму, "Another posttraumatic order" може бути способом опису уряду, де “order" описується як певна група людей, яка, можливо, стала авторитарною після низки травматичних подій, з якими стикаються лідери світу. 


\begin{tabular}{|c|c|c|c|c|c|c|c|c|c|}
\hline Song Name & 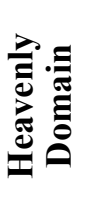 & 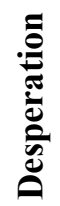 & $\frac{\stackrel{巳}{0}}{\frac{0}{0}}$ & 兄 & 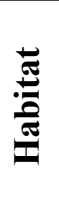 & 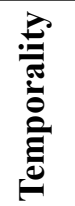 & 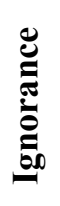 & 䒺 & $\begin{array}{l}\bar{\pi} \\
\stackrel{\bar{\theta}}{\theta} \\
\Xi\end{array}$ \\
\hline DiE4u & 2 & 3 & 4 & & & & & & 9 \\
\hline Dear Diary, & 5 & 1 & 4 & 2 & 3 & & & & 15 \\
\hline Parasite Eve & 1 & 4 & 2 & & & & 5 & & 12 \\
\hline Teardrops & & 4 & & & & & & 2 & 6 \\
\hline Obey & & & 2 & & & & & & 2 \\
\hline Kingslayer & & & 4 & & & & & & 4 \\
\hline $1 \times 1$ & & & 1 & & 2 & & & 1 & 4 \\
\hline Ludens & & 11 & 3 & & & 3 & & & 17 \\
\hline In Total & 8 & 23 & 22 & 2 & 5 & 3 & 5 & 3 & 71 \\
\hline
\end{tabular}

Рис. 1. Семантичні класи іменників у текстах пісень гурту Bring Me The Horizon

Семантичне поле VIOLENCE:

"We're only gambling with your soul" [Bring Me The Horizon, Post Human: Survival Horror]. У багатьох випадках люди навіть не знають, що їх пригнічують, і наражають своє життя на небезпеку.

"Kingslayer, destroying castles in the sky

Kingslayer, forevermore the apple of my eye

I'd sacrifice my life to find you, angel of the blade

Kingslayer, come and collect us from the night" [Bring Me The Horizon, Post Human: Survival Horror] - семантичне поле VIOLENCE. “Kingslayer" - це титул, отриманий у грі Call Of Duty, коли гравець вбиває кращого гравця ворожої команди. Тут Олівер Сайкс створює гіпотетичного персонажа, який був би "Kingslayer" нашого суспільства, людини, яка робить те, що правильно, навіть якщо це не законно. "Destroying castles in the sky" - метафора повалення урядової влади у світі.

Семантичне поле НАВITAT:

"Disconnected from the world again

And no, the sun don't shine in the place I've been" [Bring Me The Horizon, Post Human: Survival Horror]. Тут мається на увазі ізоляція від зовнішнього світу, оповідач не може вийти на вулицю та взаємодіяти з оточуючими через те, що знаходиться у замкнутому просторі.

Семантичне поле EMOTIONAL STATE:

"Put me outta my misery, my mind" [Bring Me The Horizon, Post Human: Survival Horror]. Приспів може мати два значення - особисте чи політичне. По-перше, люди можуть асоціювати його зі спогадами про погане у своєму житті.
Семантичне поле VIOLENCE:

"Feels like an archenemy, can't look me in the eyes" [Bring Me The Horizon, Post Human : Survival Horror].

Семантичне поле TEMPORALITY:

"Some resist the future, some refuse the past

Stuck in a loop for eternity" [Bring Me The Horizon, Post Human : Survival Horror].

Семантичне поле DESPERATION:

"We plot in the shadows, hang out in the gallows" [Bring Me The Horizon, Post Human: Survival Horror].

Семантичне поле VIOLENCE:

"Sticks and stones may break my bones but soon the sting will pass

But names can dig so many graves, you won't know where to stand" [Bring Me The Horizon, Post Human : Survival Horror]. Цей рядок заснований на популярній в англомовному свіиі фразі "Sticks and stones may break my bones, but words can never hurt me". Олівер Сайкс говорить про те, що хоча фізичний біль завдає страждань, слова можуть поранити набагато сильніше - фізичний біль пройде набагато швидше, ніж душевний.

Семантичне поле DESPERATION:

"I need a new leader, we need a new Luden

A new Luden, new Luden, yeah

A new Luden, new Luden, yeah

A new Luden, new Luden, yeah

A new Luden, new Luden, yeah" [Bring Me The Horizon, Post Human : Survival Horror]. Лудени - вигадана раса гуманоїдних істот, які перевершують звичайних людей, тому Олівер Сайкс каже, що “нам потрібен новий Люден”. 
Результати (рис. 1).

Висновки. У таблиці вище показано співвідношення морфо-семантичних класів іменників у тексті пісні Bring Me The Horizon: DiE4u, Dear Diary, Parasite Eve, Teardrops, Obey, Kingslayer, 1x1 та Ludens. Було доведено, що іменники, які позначають DESPERATION (23), виявилися найбільш продуктивною семантичною категорією тематичного матеріалу. Олівер Сайкс, фронтмен гурту, розповів, що з початку карантину поринув у апатію і присвятив свій новий альбом висловленню свого депресивного стану. Іншим помітним аспектом, який присутній у текстах пісень піонерів британського року, є семантичне поле іменників, які виражають VIOLENCE (22). Результат цього висновку можна знайти у назві альбому, який був проаналізований: POST HUMAN: SURVIVAL HORROR. Слово "Posthuman" походить $з$ футурології та означає сутність, яка існує за межами того стану, який ми знаємо як «людина». Попри те, що точне значення цього слова варіюється, заведено вважати, що це людина, яка завдяки генетичним маніпуляціям або іншим заходам біоінтервенції здатна залишатися здоровою та активною протягом тривалого проміжку часу, що не вважається природною за сьогоднішніми стандартами. Отже, їх потреби, а саме спрага крові, надзвичайні. Семантичний клас іменників, які позначають HEAVENLY DOMAIN, зайняв третє місце (8). Олівер Сайкс - відкритий атеїст, і він не боїться відбивати свої погляди у текстах пісень. Він стверджує, що релігія - це примітивна концепція людства для розуміння світу та його створення, вищих сил, порятунку, смерті та потойбіччя. Крім того, наш аналіз дав такі результати: семантичний клас іменників, які позначають НАBITAT (5), семантичний клас іменників, що позначають IGNORANCE (5), семантичний клас іменників, що позначають TEMPORALITY (3), семантичний клас іменників, що позначають EMOTIONAL STATE (3) семантичний клас іменників, які позначають ANIMALS (2).

\section{ЛІТЕРАТУРА}

1. Кронгауз М.А. Семантика. (2005) Издательство Академия. С. 352.

2. Сюта Б. Дискурс у музиці й теорія дискурс-аналізу в музичній науці. (2010) Студії мистецтвознавчі.

3. Chatman S., Eco U., Klinkenberg, J.M. eds. A Semiotic Landscape. Panorama sémiotique. (2019) Proceedings of the First Congress of the International Association for Semiotic Studies. Milan. Walter de Gruyter GmbH \& Co KG (Vol. 29). pp. 1268.

4. Lyons J., John L. Linguistic semantics: An introduction (1995) Cambridge University Press. pp. 376.

5. McAdams S. Psychological constraints on form-bearing dimensions in music. (1990) Contemporary Music Review, 4(1). pp. 181-198.

6. Nattiez J.J. Music and discourse: Toward a semiology of music. (1990) Princeton University Press. pp. 228.

7. Sloboda J.A. Music structure and emotional response: Some empirical findings. (1991) Psychology of music, 19(2). pp. 110-120.

\section{ДЖЕРЕЛА}

1. Bring Me The Horizon, Post Human: Survival Horror [Електронний ресурc]. URL: https://www.azlyrics.com/b/ bringmethehorizon.html (Дата звернення 26.11.2021)

\section{REFERENCES}

1. Kronhauz M.A. Semantyka. (2005) [Semantics]. Yzdatel'stvo Akademyia.

2. Siuta B. Dyskurs u muzyttsi ǐ teoriia dyskurs-analizu v muzychniǐ nauttsi. (2010) [Discourse in music and the theory of discourse analysis in music science.]. Studiï mystettstvoznavchi.

3. Chatman S., Eco U., Klinkenberg, J.M. eds. A Semiotic Landscape. Panorama sémiotique. (2019) Proceedings of the First Congress of the International Association for Semiotic Studies. Milan. Walter de Gruyter GmbH \& Co KG (Vol. 29). pp. 1268.

4. Lyons J., John L. Linguistic semantics: An introduction (1995) Cambridge University Press. pp. 376.

5. McAdams S. Psychological constraints on form-bearing dimensions in music. (1990) Contemporary Music Review, 4(1). pp. 181-198.

6. Nattiez J.J. Music and discourse: Toward a semiology of music. (1990) Princeton University Press. pp. 228.

7. Sloboda J.A. Music structure and emotional response: Some empirical findings. (1991) Psychology of music, 19(2). pp. $110-120$. 


\title{
SOURCES
}

1. Bring Me The Horizon, Post Human : Survival Horror [Electronic resource]. URL : https://www.azlyrics.com/b/ bringmethehorizon.html (Access date: 26.11.2021)

\author{
M. S. STERLIKOVA \\ Assistant Professor at the Department of English, \\ Chernivtsi National Yuri Fedkovich University, Chernivtsi, Ukraine \\ E-mail:m.sterlikova@chnu.edu.ua \\ http://orcid.org/0000-0002-2010-5518
}

\section{THE FUNCTIONAL FRAMEWORK OF NOUNS IN THE LYRICAL DISCOURSE OF THE 2010'S}

The given article examines the peculiarities of the use of nouns in the lyrics of the songs of the British independent scene of the 2010s. Nouns, which are the object of our study, are used by songwriters to denote specific culturally motivated phenomena and to convey universal concepts inherent in every individual. Linguists of all theoretical orientations agree that lexical categorization is one of the most important and complex problems in linguistics. One of the central questions of categorization is whether there is a universal semantic criterion that motivates category membership in a particular language and, more broadly, in different languages. Most modern linguists, especially those who approach this problem from the functionalist and cognitive points of view, following the traditional grammarians consider the search for conditional universals underlying category membership as a productive research program. It should be noted that the decisive point in the study of semantic classes of nouns is the extralinguistic environment, that is, the external factors that prompted the author to use certain lexical units. It can be assumed that each individual endows lexical units with a unique, intrinsic meaning, and in this regard we are confronted with several ways of interpreting song lyrics: through the prism of the songwriter and through the prism of the audience. The author of the lyrics of Bring Me The Horizon's songs is predominantly Oliver Sykes, a native of Ashford, Kent, England. Geographical location certainly played a crucial role in the songwriting process, as Bring Me The Horizon became a true British cultural phenomenon. Oliver Sykes manages not only to portray an experience that resonates with his international fans, but also to incorporate elements specific to the British collective consciousness. Having analyzed the latest Bring Me The Horizon Post Human: Survival Horror album, we identified the following semantic classes of nouns: Heavenly Domain, Desperation, Violence, Animals, Habitat, Temporality, Ignorance, Emotional State. These are the dominant categories that Oliver Sykes attempted to communicate during the COVID-19 crisis. A more detailed account of the motivations for the use of specific nouns is contained in the empirical part of the article.

Key words: semantics, semantic analysis, semantic classes of nouns, nouns, song lyrics discourse, discourse studies, the British independent music scene. 